\title{
Intercostal muscle flap reduces the pain of thoracotomy: A prospective randomized trial
}

\author{
Robert James Cerfolio, MD, FACS, FCCP, ${ }^{a}$ Ayesha S. Bryant, MSPH, MD, ${ }^{b}$ Bhavik Patel, BS, ${ }^{c}$ and \\ Alfred A. Bartolucci, $\mathrm{PhD}^{\mathrm{d}}$
}

From the Section of Thoracic Surgery, University of Alabama at Birmingham, and the Division of Cardiothoracic Surgery, Department of Surgery, Birmingham Veterans Administration Hospital, Birmingham, Ala; the Departments of Epidemiologyand Biostatistics, University of Alabama at Birmingham School of Public Health, Birmingham, Ala; and the University of Alabama School of Medicine, Birmingham, Ala.

Received for publication Jan 21, 2005; revisions received May 20, 2005; accepted for publication May 24, 2005

Address for reprints: Robert J. Cerfolio, MD, Division of Cardiothoracic Surgery, University of Alabama at Birmingham, 1900 University Blvd, THT 712, Birmingham, AL 35294 (E-mail: Robert.cerfolio@ ccc.uab.edu)

J Thorac Cardiovasc Surg 2005;130:987-93

$0022-5223 / \$ 30.00$

Copyright (C) 2005 by The American Association for Thoracic Surgery

doi:10.1016/j.jtcvs.2005.05.052
Background: Thoracotomy is associated with significant pain and morbidity.

Methods: We performed a prospective randomized trial over 4 months. Patients were randomized to a standard posterior-lateral thoracotomy or an identical procedure, except an intercostal muscle was harvested from the lower rib (to protect the intercostal nerve) before chest retraction. To ensure an equal distribution among both groups, patients were stratified by race, sex, and type of pulmonary resection. All patients received similar pain management. Pain was assessed by using multiple pain scores during hospitalization and after discharge. Outcomes assessed were pain scores, spirometric values, analgesic use, and activity level.

Results: There were 114 patients. The median time for intercostal muscle harvesting was 3.7 minutes. The numeric pain scores were lower for the intercostal muscle group on postoperative days 1 and 2 and at weeks $1,2,3,4,8$, and $12(P<.05$ for all). In addition, patients in the intercostal muscle group had a smaller decrease in spirometric values, were less likely to be using analgesics, and were more likely to have returned to normal activity.

Conclusions: The harvesting of an intercostal muscle flap before chest retraction decreases the pain of thoracotomy and leads to a lower decrease in spirometry. In addition, patients have less pain at 1, 2, 3, 4, 8, and 12 weeks postoperatively and are less likely to be using narcotics. Finally, it offers a pedicled muscle flap that takes little time to harvest and is able to buttress all bronchi after lobectomy.

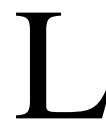
ung cancer takes the life of approximately 170,000 Americans a year. It is responsible for more deaths than the next 3 most common solid-organ cancers combined. Worldwide, it is the leading cause of cancer deaths. ${ }^{1}$ Eighty percent of patients with lung cancer have non-small cell lung cancer, which is potentially curable with surgical intervention if detected early and if completely resected. Those with stage I, II, and even IIIa disease can be cured with pulmonary resection, which is almost exclusively performed through a posterior lateral thoracotomy. ${ }^{1}$ However, thoracotomy is associated with significant pain and morbidity. Studies have shown that chronic pain (pain after 6 months) is common and can occur in up to $67 \%$ of patients. ${ }^{2-5}$ For these reasons, some have tried multiple surgical incisions and approaches, as well as minimally invasive techniques, such as video-assisted thoracoscopy (VATS). However, with VATS, one loses the ability to feel the lung, it is difficult to remove all the thoracic lymph nodes, and very few surgeons perform VATS lobectomy.

The main source of pain after thoracotomy is probably from injury to the intercostal nerve. ${ }^{6,7}$ Over the past 4 years, we have studied the problem of pain after thoracotomy by using prospective trials. ${ }^{8,9}$ In 2003, we found, in a prospective study, that sutures placed through the ribs (intracostal sutures) decreased the pain when compared with sutures that go around the ribs (paracostal sutures) during 


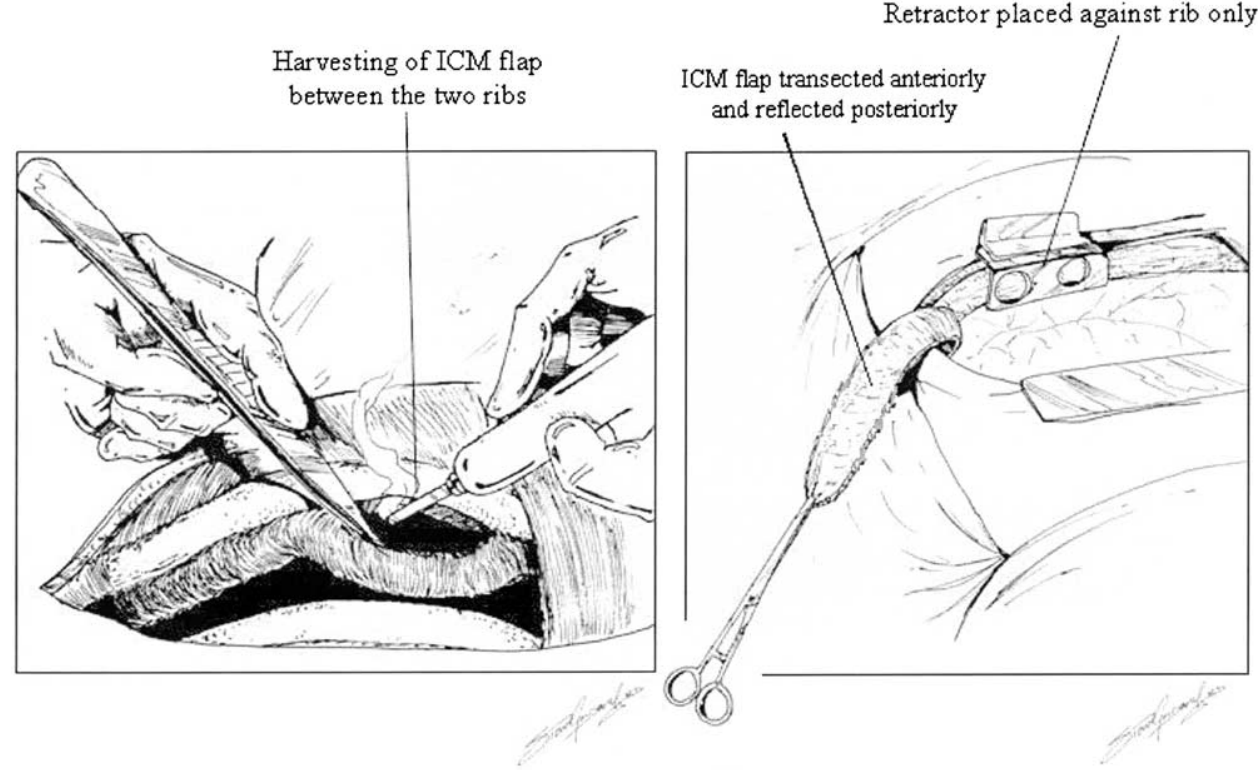

Figure 1. Intracostal muscle (ICM) flap.

closure. The former avoids entrapment of the intercostal nerve. Thus we evaluated whether we could further reduce pain by avoiding injury to the intercostal nerve during opening. We theorized that if one could take down (or harvest) part of the intercostal muscle (ICM) that lies in between the ribs and prevent it from being crushed by the upper blade of the chest retractor, the pain of a thoracotomy might be even further lessened. Thus we conducted a prospective randomized trial comparing the pain of these patients with the pain of those who underwent a standard thoracotomy (Figure 1).

\section{Material and Methods \\ Entry Criteria}

Between February 1, 2004, and July 30, 2004, all asymptomatic patients who were to undergo a posterior lateral thoracotomy for an indeterminate pulmonary nodule or for biopsy-proved nonsmall cell lung cancer performed by one general thoracic surgeon (RJC) at the University of Alabama in Birmingham were eligible for this trial. Patients were excluded if they were younger than 19 years; presented with any type of pain; had a history of chronic pain syndrome, methadone use, psychiatric illness, or previous use of opiates or steroids 6 month before the operation; had a previous thoracotomy; received neoadjuvant therapy; or refused entry into the trial. If sleeve lobectomy or pneumonectomy was anticipated, patients were excluded because an ICM flap was used to cover the bronchi. Patients who presented with chest pain or asymptomatic patients with radiologic evidence of parietal pleural or rib invasion were also excluded. Careful preoperative assessment, including pulmonary function tests, cardiac stress tests, echocardiography, computed tomography, and positron emission tomography, were performed in all patients.
In addition, patients had spirometry performed during their preoperative clinic visit. This was performed by asking the patient to take 2 deep breaths and then blow out as hard as possible into the incentive spirometer 3 times. The spirometric value for each breath was recorded and averaged. The same technique was used each day in the hospital.

Patients meeting the enrollment criteria were randomly assigned the day of the operation to either the ICM group or the standard group. They were stratified by race, sex, and resection type to ensure an equal distribution of patients in the 2 groups. Only the surgeon and his surgical team were aware of the patient assignment. Office staff, who were responsible for surveying patients, performing data entry, and performing telephone surveys, as well as the patients themselves, were blinded to the patient randomization assignment.

\section{Intraoperative Technique}

All patients had an epidural placed preoperatively before the operation. If the epidural was deemed to be nonfunctional at any time postoperatively by the pain service, the patient was eliminated from the study. If patients had significant complications (ie, confusion, transfer to the intensive care unit, or requirement for intubation) that precluded them from participating in the study, they were also eliminated. If patients had prolonged air leaks and were sent home with a chest tube in place on a Heimlich valve, they were also excluded. All openings and closings were performed by one surgeon, with various cardiothoracic fellows and general surgical residents. All patients had skin incisions the length of the posterior half of their latissimus dorsi muscle. The posterior half of the latissimus dorsi was cut, and the entire serratus anterior muscle was preserved. Once the sixth rib was identified, the ICM above it, as well as 2 ICM bundles above and 2 below, were all injected with bupivacaine (Marcaine; Abbott Labs, North Chicago, 
Ill) with epinephrine. The maximum dose of bupivacaine was calculated, and $50 \%$ of this dose was drawn into a syringe. It was then injected evenly into the 5 ICMs with an 18-gauge needle. The chest was entered over the top of the sixth rib in all patients. The rib was not cut or shingled. At this point, the surgeon was made aware of into which group the patient was randomized. Those patients randomized to the standard group had the chest retractor placed with one blade against the sixth rib and the other against the fifth ICM that was still attached to the lower aspect of the fifth rib. Those patients randomized into the ICM group had the fifth ICM harvested off of the inferior edge of the fifth rib by use of a cautery. The muscle was deflected downward with a forceps during the harvesting, which allows the flap to remain viable so it can be used later to cover or buttress the bronchi after lobectomy. The ICM was taken down off most of the rib. It was cut just under the serratus anterior muscle, and posteriorly it was kept intact because the blood supply comes from this area. During the pulmonary resection, the muscle was retracted out of the way. We attempted to avoid rib fracture by slowly opening the chest retractor.

After completion of the appropriate pulmonary resection and thoracic lymphadenectomy, patients had one or two $28 \mathrm{~F}$ soft chest tubes placed. Patients who underwent lobectomy had 2 tubes placed; patients who had a segmentectomy and wedge resection received only 1 tube. All patients had intracostal sutures used for closure. Patients then received identical postoperative pain regimens. Epidurals were removed on the morning of postoperative day (POD) 2 in all patients, and oxycodone and acetametaphin (Tylox; McNeil Pharmaceuticals, Springhouse, Pa) were used as well. Ketorolac tromethamine (INN: ketorolac; Toradol, Nutley, $\mathrm{NJ}$ ) was administered to all patients in the recovery room and daily until POD 2 as well. Intravenous morphine was used for breakthrough pain. Members of the pain service who managed the epidural and the nurses on our team, nurses on the floor, and data collectors were all blinded to patient randomization assignment.

\section{Pain Score Assessment}

Postoperatively, pain scores were objectively measured and recorded. The numeric rating scale,${ }^{10}$ visual pain score,${ }^{11}$ and verbal descriptor scale ${ }^{12}$ were used for patients while hospitalized.

Each patient was interviewed each day between 3 PM and 7 PM by a blinded study coordinator. Interviews were conducted by using the same script each day. Patients usually received oral analgesics between 2 PM and 6 PM. The amount of pain medicines used was also recorded. In-hospital complications were noted, and daily chest roentgenograms were performed.

Once discharged, the visual pain assessment score was not used; however, the numeric and descriptive scales were used. One of 2 interviewers called patients at home and assessed their pain using a standard outpatient script. The calls were made between 1 PM and 5 PM at postoperative weeks 1, 2, 4, 8, and 12. If patients returned for a 3 -week postoperative check in the clinic, a numeric pain score was recorded by using the same script as in the hospital. The amount of pain medicines used was also recorded. The Institutional Review Board of the University of Alabama in Birmingham approved this study, along with the prospective database used concomitantly.
TABLE 1. Patient and pathologic characteristics*

\begin{tabular}{|c|c|c|}
\hline & ICM group & Standard grou \\
\hline No. of patients & 56 & 58 \\
\hline Mean age (y) & 66 & 65 \\
\hline \multicolumn{3}{|l|}{ Sex } \\
\hline Male & $29(52 \%)$ & $30(52 \%)$ \\
\hline Female & $27(48 \%)$ & $28(48 \%)$ \\
\hline \multicolumn{3}{|l|}{ Race } \\
\hline White & $49(88 \%)$ & $50(86 \%)$ \\
\hline Black & $7(12 \%)$ & $8(14 \%)$ \\
\hline BMI (mean) & 30.5 & 29 \\
\hline \multicolumn{3}{|l|}{ Pulmonary function test } \\
\hline $\mathrm{FEV}_{1}(\%)$ & 81 & 72 \\
\hline $\operatorname{MVV}(\%)$ & 62 & 64 \\
\hline DLCO (\%) & 84 & 76 \\
\hline \multicolumn{3}{|l|}{ Types of procedure } \\
\hline Segmentectomy & $6(11 \%)$ & $7(12 \%)$ \\
\hline Lobectomy & $37(66 \%)$ & $38(66 \%)$ \\
\hline Wedge & $13(23 \%)$ & $13(22 \%)$ \\
\hline \multicolumn{3}{|l|}{ Stage } \\
\hline Benign & $10(18 \%)$ & $14(24 \%)$ \\
\hline $\mathrm{la}, \mathrm{lb}$ & $12(21 \%)$ & $12(21 \%)$ \\
\hline Ila, IIb & $20(36 \%)$ & $19(33 \%)$ \\
\hline IIla, IIIb & $3(5 \%)$ & $2(4 \%)$ \\
\hline IV & $3(6 \%)$ & $4(7 \%)$ \\
\hline Metastatic disease & $8(14 \%)$ & $7(2 \%)$ \\
\hline \multicolumn{3}{|l|}{ Histology } \\
\hline $\begin{array}{l}\text { Benign, infectious, or } \\
\text { inflammatory }\end{array}$ & $12(22 \%)$ & $15(26 \%)$ \\
\hline \multicolumn{3}{|l|}{ cause } \\
\hline Adenocarcinoma & $17(30 \%)$ & $18(30 \%)$ \\
\hline $\begin{array}{l}\text { Squamous cell } \\
\text { carcinoma }\end{array}$ & $14(25 \%)$ & $14(24 \%)$ \\
\hline Other NSCLC & $5(9 \%)$ & $5(9 \%)$ \\
\hline Metastatic nodule & $8(14 \%)$ & $7(12 \%)$ \\
\hline
\end{tabular}

ICM, Intercostal muscle; $B M I$, body mass index; $F E V_{1}$, forced expiratory volume in 1 second; $M V V$, maximal voluntary ventilation; $D L C O$, diffusion capacity of the lung for carbon monoxide; NSCLC, non-small cell lung cancer. $* P>.05$ for all variables.

\section{Statistical Analysis}

A power analysis performed before commencing this study indicated that a total of 150 patients ( 75 patients in each group) were needed. An interim analysis was planned to be performed after approximately 50 patients were enrolled in each group. Data for all patients who were randomly assigned to a group were analyzed on an intention-to-treat basis. Given the need to randomize patients before the operation in this study, patients who had significant operative morbidity were excluded from the study and any analysis. Patient characteristics are provided in Table 1.

For the analysis of differences between groups, we used 2-tailed $t$ tests, or if the results were not normally distributed, we used nonparametric tests. Fisher exact or $\chi^{2}$ tests were used to compare proportions. An analysis of variance for repeated measurements was performed to compare the pain scores for the 2 groups. Time to the resumption of normal activity (ie, percentages 
TABLE 2. Reasons for exclusions from trial after randomization

\begin{tabular}{|c|c|c|c|}
\hline Reason for exclusion & $\begin{array}{l}\text { ICM } \\
\text { group }\end{array}$ & $\begin{array}{l}\text { Standard } \\
\text { group }\end{array}$ & Total \\
\hline Loss to follow-up & 2 & 3 & 5 \\
\hline $\begin{array}{l}\text { Epidural nonfunctional or } \\
\text { accidentally dislodged }\end{array}$ & 3 & 2 & 5 \\
\hline $\begin{array}{l}\text { Patients transferred to ICU } \\
\text { for cardiac shock, stroke, } \\
\text { ARDS }\end{array}$ & 2 & 3 & 5 \\
\hline $\begin{array}{l}\text { Sent home with chest tube in } \\
\text { on Heimlich valve }\end{array}$ & 4 & 8 & 12 \\
\hline $\begin{array}{l}\text { Marcaine not injected into } \\
\text { ribs before rib spreading }\end{array}$ & 0 & 1 & 1 \\
\hline $\begin{array}{l}\text { Tumor growing into parietal } \\
\text { pleural surface of } \\
\text { intercostal muscle }\end{array}$ & 1 & 0 & 1 \\
\hline $\begin{array}{l}\text { Refused to answer } \\
\text { postoperative pain survey }\end{array}$ & 0 & 1 & 1 \\
\hline Required chest wall resection & 0 & 1 & 1 \\
\hline Total & 12 & 19 & 31 \\
\hline
\end{tabular}

ICM, Intercostal muscle; ICU, intensive care unit; $A R D S$, adult respiratory distress syndrome.

for categoric variables) was analyzed with Kaplan-Meier survival curves, and differences between the 2 treatment groups were compared by using the log-rank test.

\section{Results}

One hundred eighty-one patients underwent elective pulmonary resection during this time frame, and 145 (77\%) met the entry criteria, agreed to enroll in the study, and were randomized. Of those randomized, 114 (78\%) patients remained in the study. Table 1 shows the randomization was successful because there were no statistically significant differences between patients in the ICM and standard groups for previously identified variables for pain. Table 2 shows the reasons for the elimination of 31 patients after randomization.

\section{Intraoperative Outcomes}

Patients randomized to the ICM group had a higher incidence of a broken rib compared with those randomized to the standard group (19 [34\%] vs 8 (13\%), respectively; $P=$ $.025)$. The mean time to perform an ICM procedure was 3.7 minutes. The mean number of chest tubes placed was the same for both groups (2). The mean days of hospital length of stay (4.32 vs. 4.39 days, respectively) and number of patients who received adjuvant chemotherapy ( 7 vs 5 , respectively) for the ICM and standard groups were relatively similar.

\section{In-hospital Outcomes}

Table 3 depicts the pain scores in the hospital for each POD. It shows patients in the ICM group had a significantly lower numeric pain score on PODs 1 and 2, a lower visual pain score on PODs 1 (2.29 vs 4.5) and 2 (2.91 vs 4.38, $P=.04$ ), and also a lower visual pain score on POD 1 for the patients in the ICM group compared with those in the standard group (1.6 vs $2.27, P=.04$ ). There were no statistically significant differences seen in the outcomes of the descriptor pain score. Almost all patients in both groups were ambulatory starting on POD 1. Patients in the ICM group had less of a decrease in their spirometry values on all PODs, with a statistically significant difference on PODs 2 and 3. There was no difference between the 2 groups for the amount of pain medicine used while in the hospital. Hospital complications are shown in Table 4. Only 1 patient in the ICM group had pulmonary complications (other than prolonged

TABLE 3. Pain assessment for the 2 groups during the hospitalization

\begin{tabular}{|c|c|c|c|c|c|c|c|c|}
\hline & ICM group & $\begin{array}{l}\text { Standard } \\
\text { group }\end{array}$ & ICM group & $\begin{array}{l}\text { Standard } \\
\text { group }\end{array}$ & ICM group & $\begin{array}{c}\text { Standard } \\
\text { group }\end{array}$ & ICM group & $\begin{array}{c}\text { Standard } \\
\text { group }\end{array}$ \\
\hline Postoperative day & 1 & 1 & 2 & 2 & 3 & 3 & 4 & 4 \\
\hline No. of patients & 56 & 58 & 55 & 54 & 51 & 52 & 42 & 43 \\
\hline Numeric rating scale(of 10$)$ & $2.29(P=.04)$ & 4.50 & $2.91(P=.04)$ & 4.38 & 2.54 & 2.81 & 2.37 & 2.56 \\
\hline Visual (of 6) & $1.60(P=.03)$ & 2.27 & 2.24 & 2.48 & 1.79 & 1.86 & 1.51 & 1.76 \\
\hline $\begin{array}{l}\text { Descriptor, patients w/mild } \\
\text { to no pain }\end{array}$ & $86 \%(48)$ & $71 \%(41)$ & $95 \%(52)$ & $93 \%(50)$ & $86 \%(44)$ & $92 \%(48)$ & $97 \%(41)$ & $95 \%(41)$ \\
\hline Decrease in spirometry & $53 \%$ & $44 \%$ & $28 \%(P=.03)$ & $36 \%$ & $11 \%(P=.02)$ & $23 \%$ & $16 \%$ & $35 \%$ \\
\hline Patients ambulatory & $100 \%$ & $98 \%$ & $100 \%$ & $100 \%$ & $100 \%$ & $100 \%$ & $100 \%$ & $100 \%$ \\
\hline Patients epidural & $100 \%$ & $100 \%$ & $5.4 \%(3)$ & $3.8 \%(2)$ & $0 \%$ & $0 \%$ & $0 \%$ & $0 \%$ \\
\hline $\begin{array}{l}\text { Patients with chest tube(s) } \\
\text { in place }\end{array}$ & $100 \%(56)$ & $100 \%(58)$ & $69 \%(38)$ & $69 \%(37)$ & $27 \%(14)$ & $31 \%(16)$ & $5.2 \%(8)$ & $7.3 \%(7)$ \\
\hline $\begin{array}{l}\text { Patients using PO pain } \\
\text { medications }(\%)\end{array}$ & $0 \%$ & $5 \%(3)$ & $94 \%(50)$ & $96.4 \%(54)$ & $100 \%$ & $100 \%$ & $100 \%$ & $100 \%$ \\
\hline
\end{tabular}

Means are reported, and statistically significant $P$ values that favor one group appear under that group's score. ICM, Intercostal muscle; $P O$, by mouth. 
TABLE 4. Patient complications while in the hospital

\begin{tabular}{|c|c|c|}
\hline & ICM group & Standard group \\
\hline No. of patients & 56 & 58 \\
\hline \multicolumn{3}{|l|}{ Pulmonary } \\
\hline Pneumonia & 1 & 3 \\
\hline Reintubated & 0 & 1 \\
\hline \multicolumn{3}{|l|}{$\mathrm{GI}$} \\
\hline lleus & 1 & 1 \\
\hline Diverticulitis & 1 & 0 \\
\hline \multicolumn{3}{|l|}{ Cardiovascular } \\
\hline Atrial arrhythmia* & 4 & 13 \\
\hline \multicolumn{3}{|l|}{ Urinary } \\
\hline Urinary retention & 1 & 0 \\
\hline Total* & 8 & 18 \\
\hline
\end{tabular}

ICM, Intercostal muscle; GI, gastrointestinal. *Significantly different $(P<$ $.05)$.

air leak) during hospitalization compared with 4 patients in the standard group.

\section{Long-Term/Outpatient Outcomes}

An analysis of variance showed that the patients in the ICM group had lower numeric pain scores than the patients in the standard group $(P=.004)$. Table 5 shows the numeric pain scores at each week postoperatively. A pain score was also obtained during the patients' 3 -week postoperative clinic visits. The difference between the 2 groups achieved statistical significance at all weeks measured $(1,2,3,4,8$, and 12). Those in the ICM groups were less likely to use analgesics at 2, 4, 8, and 12 weeks postoperatively, and this difference was statistically significant at weeks 4 and 8 . In addition, patients in the ICM group were more likely to return to their normal daily activities sooner than those patients randomized to the standard group (3 weeks compared with 8 weeks, respectively; $P=.0219$ ).

\section{Discussion}

Pain is inherently difficult to study because by its nature it is subjective. For these reasons, over the past several years, we have performed studies designed to limit as many confounding variables as possible. We have used only one surgeon who, despite the presence of surgical assistants, residents, and fellows, opens and closes all patients. We have used identical selection criteria, intraoperative techniques, and postoperative management and changed only one small variable at a time. We have applied the best available scores, scales, and measurements of pain to objectify pain and to quantify it as best as possible. And we have used only prospective trials, prospective randomized trials, or both. Yet no study that assesses a patient's pain is perfect.

TABLE 5. Postoperative assessment

\begin{tabular}{|c|c|c|c|c|c|c|c|c|c|c|c|c|}
\hline & ICM group & $\begin{array}{c}\text { Standard } \\
\text { group }\end{array}$ & $\begin{array}{c}\text { ICM } \\
\text { group }\end{array}$ & $\begin{array}{c}\text { Standard } \\
\text { group }\end{array}$ & $\begin{array}{c}\text { ICM } \\
\text { group }\end{array}$ & $\begin{array}{c}\text { Standard } \\
\text { group }\end{array}$ & $\begin{array}{c}\text { ICM } \\
\text { group }\end{array}$ & $\begin{array}{c}\text { Standard } \\
\text { group }\end{array}$ & $\begin{array}{c}\text { ICM } \\
\text { group }\end{array}$ & $\begin{array}{c}\text { Standard } \\
\text { group }\end{array}$ & $\begin{array}{c}\text { ICM } \\
\text { group }\end{array}$ & $\begin{array}{c}\text { Standard } \\
\text { group }\end{array}$ \\
\hline Postoperative wk & 1 & 1 & 2 & 2 & $3^{*}$ & $3^{*}$ & 4 & 4 & 8 & 8 & 12 & 12 \\
\hline No. surveyed & 56 & 57 & 54 & 53 & 35 & 36 & 48 & 45 & 44 & 42 & 40 & 38 \\
\hline $\begin{array}{l}\text { Numeric rating } \\
\text { score }\end{array}$ & $2.63 \dagger$ & 4.0 & $2.13 t$ & 3.44 & $0.51 \dagger$ & 2.40 & $1.5 \dagger$ & 2.8 & $1.32 \dagger$ & 2.53 & $1.2 \dagger$ & 2.68 \\
\hline $\begin{array}{l}\text { Verbal descriptor } \\
\text { scale, patients } \\
\text { who reported } \\
\text { mild or no } \\
\text { discomfort }\end{array}$ & $\begin{array}{c}91 \%(51) \\
P=.03\end{array}$ & $79 \%(42)$ & $88 \%(48)$ & $79 \%(42)$ & NA & NA & $92 \%(44)$ & $84 \%(38)$ & $88 \%(39)$ & $88 \%(37)$ & $78 \%$ & $72 \%$ \\
\hline $\begin{array}{l}\text { Patients } \\
\text { readmitted } \\
\text { within } 30 \mathrm{~d} \text { of } \\
\text { the operation }\end{array}$ & $2 \%(1)$ & $2 \%(1)$ & $5.6 \%(3)$ & $4 \%(2)$ & NA & NA & $10.4 \%(5)$ & $6.7 \%(3)$ & NA & NA & NA & NA \\
\hline $\begin{array}{l}\text { Patients using } \\
\text { pain medicine }\end{array}$ & $95 \%(53)$ & $95 \%(54)$ & $81 \%(44)$ & $91 \%(48)$ & NA & NA & $35 \%+(17)$ & $62 \%(28)$ & $16 \% \dagger(7)$ & $41 \%(18)$ & $8 \%(3)$ & $13 \%(5)$ \\
\hline $\begin{array}{l}\text { Patients } \\
\text { receiving } \\
\text { adjuvant } \\
\text { treatment }\end{array}$ & 0 & 0 & 0 & 0 & 0 & 0 & 4 & 3 & 7 & 6 & 9 & 8 \\
\hline $\begin{array}{l}\text { Patients satisfied } \\
\text { with procedure } \\
\text { and care }\end{array}$ & $95 \%(53)$ & $96 \%(55)$ & $96 \%(52)$ & $98 \%(52)$ & $100 \%$ & $100 \%$ & $92 \%(44)$ & $100 \%(45)$ & $89 \%(39)$ & $88 \%(37)$ & $88 \%(35)$ & $84 \%(32)$ \\
\hline
\end{tabular}

ICM, Intercostal muscle; $N A$, not applicable. *Pain score assessed in person at time of postoperative clinic visit, which was normally done during the third week postoperatively. $\uparrow P<.05$. 
In this prospective randomized trial, we have shown that the avoidance of retraction on the ICM and the nerve that runs in it significantly reduces pain. In fact, this study was stopped early because of the statistically significant differences between the 2 groups. The strengths of this study are its strict methodology, including rigid inclusion-exclusion criteria, set times, and standardized scripts for patient pain surveys; the use of 3 different pain scales; and the evaluation of objective data, such as the spirometric measurements and pain medication use. The limitations of our study lie within the subjective nature of pain itself.

Surprisingly, we also found that those patients in the ICM group had less pain during the first and second days of hospitalization, despite the fact that all patients had functioning epidurals and other analgesics available to them. Perhaps most important is that this decrease in pain might allow patients to breathe deeper, and this could reduce some respiratory complications, such as pneumonia and mucous plugging, which remain significant vexing problem after thoracotomy and pulmonary resection. The pathophysiologic mechanism for this result can be seen in another finding in this study: spirometry. Patients in the ICM group had less of a reduction of their spirometric values than those in the standard group. Perhaps an ICM flap further reduces postoperative pain and allows patients to breath deeper and better aerate the lung. Further studies are needed to corroborate this finding and the precise physiology.

An ICM flap is easy to perform, does not require any special equipment, and takes little time. However, occasionally, a cancer invades that part of the chest wall or the parietal pleural that runs under the ICM. In this situation it must be resected en block with the cancer. We also found that when the ICM was harvested, we were more likely to break the lower rib. This might be because the upper rib is less protected after the muscle has been removed from much of its surface. Interestingly, however, we did not find that having a broken rib was associated with more pain. This might be because we ensured that when we closed the chest, the ends of the broken ribs were well secured together and not rubbing.

The ideal way to perform a thoracotomy to minimize pain is not known. However, the best treatment of pain might be prevention. This is based on the peripheral and central hypersensitivity that occurs after tissue or nerve injury. ${ }^{13,14}$ A study by Katz and colleagues ${ }^{5}$ demonstrated that patients with long-term pain were more likely to have had significantly greater pain intensity 24 hours after surgical intervention. Therefore modification of surgical techniques that can decrease acute pain might also decrease chronic pain. Some surgeons prefer a vertical axially thoracotomy, ${ }^{15}$ and others prefer a muscle-sparing thoracotomy. ${ }^{7,16}$ Previous prospective randomized trials showed no benefit for a muscle-sparing thoracotomy when compared with a non-muscle-sparing technique. ${ }^{17} \mathrm{We}$ performed a prospective trail in 2003 and found that avoiding the nerve at closure can significantly decrease pain. It also changed the patient's perception of that pain and made it less likely to be described as "searing" or "burning."

The concept of harvesting an ICM flap is probably not new. Since performing this study, we have become aware that some surgeons have used it. However, its advantages have never been critically studied. When we used both the ICM flap and the intercostal sutures, we eliminated the problem of chronic pain (pain after 6 moths) in all patients thus far. The vast majority of patients are therefore able to undergo posterior-lateral thoracotomy, pulmonary resection, and complete thoracic lymphadenectomy and have a pain score of only 1,2, or 3 at 3 to 4 weeks postoperatively. Most are off of all narcotics, are back at work, and are able to resume all physical activities without restriction. Those in the ICM group were more likely to have returned to their baseline activities by 1 month compared with those in the standard group.

On the basis of these findings, we recommend the use of an ICM flap as a way to decrease the pain of thoracotomy. In addition, it affords a versatile and vascularized muscle that is extremely useful. It can be used to buttress all bronchi after lobectomy or segmentectomy. It can also be used to support or cover esophageal repair. Coverage of the bronchi is recommended after pneumonectomy and for the patients who are at risk of bronchopleural fistula. ${ }^{18}$ This includes those who have had preoperative radiation or chemotherapy and those who are immunocompromised. When harvested as described in this study, an ICM flap is devoid of periosteum, and it does not calcify over time. Our future plans are to study further reduction in pain by leaving the nerve intact distally, without division of the ICM, and yet still avoid the nerve from being crushed by the retractor.

In conclusion, the harvesting of an ICM flap is a simple surgical modification to thoracotomy that can decrease acute and chronic pain. This reduction in pain leads to less decrease in spirometric values. This technique reduces pain after discharge at 1, 2, 3, 4, 8, and 12 weeks postoperatively. Patients were less likely to require analgesics and were more likely to have returned to normal activities by 1 month.

We thank Cyndi Bass, RN, MSN, CRNP; Jeana Alexander, $\mathrm{RN}$; and Sandra Calloway and Steven Goldberg, MD, for their assistance with this trial and with the care of these patients.

\section{References}

1. Spira A, Ettinger DS. Multidisciplinary management of lung cancer. N Engl J Med. 2004;350:379-92.

2. Kalso E, Perttunen K, Kassinen S. Pain after thoracic surgery. Acta Anaesthesiol Scand. 1992;36:96-100.

3. Matsunaga M, Dan K, Manable FY, et al. Residual pain of 90 thoracotomy patients with malignancy and non-malignancy. Pain. 1990; (suppl 5):S148.

4. Kanner RM, Martini N, Foley KM. Nature and incidence of postthoracotomy pain. Proc Am Soc Clin Oncol. 1982;1:152. 
5. Katz J, Jackson M, Kavanagh BP, et al. Acute pain after thoracic surgery predicts long-term post-thoracotomy pain. Clin J Pain. 1996; 12:50-5.

6. Toledo-Pereyra LH, Demeester TR. Prospective randomized evaluation of intrathoracic intercostals nerve block with bupivacaine on postoperative ventilatory function. Ann Thorac Surg. 1979;27:203-5.

7. Hazelrigg SR, Landreneau RJ, Boley TM, et al. The effect of muscle sparing versus posterolateral thoracotomy on pulmonary function, muscle strength, and postoperative pain. J Thorac Cardiovasc Surg. 1991;101:394-401.

8. Cerfolio RJ, Bryant AS, Bass CS, et al. A prospective, double-blinded, randomized trial evaluating the use of preemptive analgesia of the skin before thoracotomy. Ann Thorac Surg. 2003;76:1055-8.

9. Cerfolio RJ, Price TN, Bryant AS, et al. Intracostal sutures decrease the pain of thoracotomy. Ann Thorac Surg. 2003;76:407-11.

10. Downie WW, Leatham PA, Rhind PA, et al. Studies with pain rating scales. Ann Rheum Dis. 1978;37:378-81.
11. Wong D. Whaley \& wong's essentials of pediatric nursing. 5th ed. New York: Mosby-Year Book Inc; 1997. p. 1215.

12. Keele KD. The pain chart. Lancet. 1948;2:6-8.

13. Fitzgerald $M$. The spread of sensitization of polymodal nociceptors in the rabbit from nearby injury and by antidromic nerve stimulation. J Physiol. 1979;297:207-16.

14. Dubner R. Pain and hyperalgesia following tissue injury new mechanisms and new treatments. Pain. 1991;44:213-4.

15. Baeza OR, Foster ED. Vertical axillary thoracotomy: a functional and cosmetically appealing incision. Ann Thorac Surg. 1988;123:113-4.

16. Bethencourt DM, Holmes EC. Muscle-sparing posterolateral thoracotomy. Ann Thorac Surg. 1988;45:337-9.

17. Kittle CF. Which way in? Thoracotomy incision. Ann Thorac Surg. 1988;45:234.

18. Sonett JR, Suntharalingam M, Edelman MJ, et al. Pulmonary resection after curative intent radiotherapy $(>59 \mathrm{~Gy})$ and concurrent chemotherapy in non-small cell lung cancer. Ann Thorac Surg. 2004;78: 1200-6.

\section{JTCVS On-Line Manuscript Submission and Review}

The Journal of Thoracic and Cardiovascular Surgery requires authors and reviewers to submit all new and revised manuscripts and reviews via Editorial Manager. Point your browser to http://jtcvs.editorialmanager.com, log in as author or reviewer (as appropriate), and follow the instructions provided.

To retrieve your username and password, click "Forget your password?" on the Editorial Manager log-in page.

If you have questions or experience problems uploading your manuscript or review, please contact the editorial office:

Telephone: 215-762-1854

E-mail: jtcvs@drexel.edu 